\title{
Risk factors for peripherally inserted central catheter (PICC)-associated infections in patients receiving chemotherapy and the preventive effect of a self-efficacy intervention program: a randomized controlled trial
}

\author{
Xiaoman Liu ${ }^{1 \#}$, Shuo Tao ${ }^{2 \#}$, Haixia Ji ${ }^{1}$, Siqi Chen ${ }^{3}$, Yan $\mathrm{Gu}^{4}$, Xiaohong Jin ${ }^{1}$ \\ ${ }^{1}$ Department of Ophthalmology, Affiliated Hospital of Nantong University, Nantong, China; ${ }^{2}$ Department of Nephrology, Second Affiliated Hospital \\ of Nantong University, Nantong, China; ${ }^{3}$ Student, Affiliated Hospital of Nantong University, Nantong, China; ${ }^{4}$ Department of Nursing, Affiliated \\ Hospital of Nantong University, Nantong, China \\ Contributions: (I) Conception and design: X Liu, S Tao; (II) Administrative support: X Jin; (III) Provision of study materials or patients: H Ji; (IV) \\ Collection and assembly of data: S Chen; (V) Data analysis and interpretation: Y Gu; (VI) Manuscript writing: All authors; (VII) Final approval of the \\ manuscript: All authors. \\ \#These authors contributed equally to this work. \\ Correspondence to: Xiaohong Jin. Department of Ophthalmology, Affiliated Hospital of Nantong University, Nantong, China. \\ Email: 470504752@qq.com; Yan Gu. Department of Nursing, Affiliated Hospital of Nantong University, Nantong, China. Email: yeziyeok@163.com.
}

Background A peripherally inserted central catheter (PICC) effectively reduces frequent vein punctures in cancer patients. With increasing clinical applications, PICC-associated infections are attracting increasing attention. In this study, we retrospectively analyzed PICC-associated infections in chemotherapy patients treated at our hospital in recent years to identify risk factors for PICC-associated infections and the preventive effect of a self-efficacy intervention program.

Methods: Using a convenience sampling method, we selected 159 cancer patients who received chemotherapy through a PICC at our hospital between July 2017 and December 2018, and the patients were randomly divided to an observation group $(n=79)$ and a control group $(n=80)$ using a random number table. The control group received conventional intervention, and the observation group received a self-efficacy intervention. We analyzed self-efficacy scores before and after the intervention, the complication rate, the infection rate, pathogens identified, and risk factors for PICC-associated infections.

Results: Among the 159 chemotherapy patients, 26 (16.35\%) experienced PICC-associated infections in this finished trial. Univariate analysis showed that sex, puncture site, and steroid use were unrelated to PICC-associated infections ( $\mathrm{P}>0.05)$, whereas PICC indwelling time, white blood cell (WBC) count, a history of diabetes, and immunity were significantly related to $\mathrm{PICC}$-associated infections $(\mathrm{P}<0.05)$. The self-efficacy score improved after the intervention in both groups, especially in the observation group $(\mathrm{P}<0.05)$. The incidence of complications such as catheter infection, catheter blockage, and catheter displacement was significantly lower in the observation group than in the control group (16. 67\% vs. $88.10 \% ; \mathrm{P}<0.05)$.

Conclusions: The self-efficacy intervention improves self-management and reduces complications in cancer patients receiving chemotherapy through a PICC. PICC indwelling time, WBC count, a history of diabetes, and immunity are independent risk factors for PICC-associated infections; thus, measures should be implemented to prevent infections.

Trial Registration: Chinese Clinical Trial Registry ChiCTR2100050651.

Keywords: Chemotherapy; self-efficacy; central venous catheter; risk factors

Submitted Mar 10, 2021. Accepted for publication Sep 18, 2021.

doi: 10.21037/apm-21-1848

View this article at: https://dx.doi.org/10.21037/apm-21-1848 


\section{Introduction}

Cancer is a common disease with high morbidity and mortality. Long treatment courses and frequent punctures increase the risk of vessel injury, which causes significant discomfort to patients $(1,2)$. A peripherally inserted central catheter (PICC) for chemotherapy administration effectively reduces frequent punctures and ensures the safety of chemotherapy drugs, providing a long-term treatment option for cancer patients while reducing discomfort (3). Under the situation of continuous infusion of chemotherapeutics, or irritating and corrosive chemotherapeutics, the PICC was needed for the success of implementation of chemotherapy. Recent studies $(4,5)$ show that PICCs effectively reduce discomfort, punctures, and phlebitis and are therefore widely used in clinical practice. However, A recent study (6) show that catheter-associated infection is one of the most common complications of a long PICC indwelling time, which affects treatment outcomes, prolongs hospital stays, increases medical expenses, and causes significant inconvenience to patients. Therefore, PICC-associated infections and relevant risk factors are hot topics among clinical researchers. The rate of complications at catheter insertion was $5.8 \%$ for PICC (7). Previous study (8) show that appropriate interventions in chemotherapy patients with an indwelling PICC reduce complication and infection rates during chemotherapy by improving patients' self-management. Self-efficacy refers to the subjective judgment of self-perception of successful completion of a certain goal or behavior, which can reflect the subjective evaluation and cognition of the individual's own behavioral ability. Self-efficacy intervention has been widely used in multiple types of cancers, and satisfactory results have been achieved in the nursing of patients with malignant tumors. In the present study, a retrospective analysis on the occurrence of PICC-related infections in chemotherapy patients was performed in our hospital in recent years. We aimed at to study the independent risk factors of PICC-related infection in chemotherapy patients to control the occurrence of infection effectively, which might provide novel principles on clinical prevention, and therapy of PICC-related infections. The results are reported below. We present the following article in accordance with the CONSORT reporting checklist (available at https://dx.doi.org/10.21037/apm-21-1848).

\section{Methods}

\section{General information}

This was a two-parallel randomized controlled trial.
The allocation ratio was closed to 1:1 (79:80). Using a convenience sampling method, we selected 159 cancer patients who received chemotherapy at our hospital between July 2017 and December 2018 and randomly divided the patients to an observation group $(\mathrm{n}=79)$ and a control group $(\mathrm{n}=80)$ using a random number table. The observation group included 19 men and 60 women aged $50.51 \pm 7.02$ years, and the control group included 21 men and 59 women aged $38.97 \pm 6.89$ years. The inclusion criteria (9) included (I) a malignant tumor and an indwelling PICC; (II) a PICC indwelling for one week or more without any complications; and (III) consciousness with the ability to express ideas. The exclusion criteria included (I) allergies to catheter materials; (II) skin damage at the puncture site; (III) coagulation disorders or severe bleeding disorders; or (IV) any other infection. The study was approved by the Ethics Committee of Affiliated Hospital of Nantong University. The study was conducted in accordance with the Declaration of Helsinki (as revised in 2013). Written informed consent was obtained from all patients. The patients' general information was comparable between the two groups $(\mathrm{P}>0.05)$.

\section{Study methods}

Control group: a conventional intervention, including instructions at discharge, general care, diet management, chemotherapy-related care, and mental care, was provided.

Observation group: a self-efficacy intervention was provided, including (I) a self-efficacy healthcare team with self-efficacy training, including 1 group leader and 5 responsible nurses; (II) an individualized health plan and a behavior contract with each patient to encourage and affirm self-efficacy behaviors, including monthly meetings to watch and discuss home care videos of PICC patients to educate patients and facilitate peer face-to-face communications to help patients improve confidence and live with their condition; and (III) individualized education to teach PICC maintenance and self-management techniques and build rapport with the patient to work together to achieve the treatment goals.

Sex, puncture site, PICC indwelling time, steroid use, immunity, white blood cell (WBC) counts, and history of diabetes were recorded and analyzed to develop intervention strategies. Samples from patients with PICCassociated infections were tested to identify pathogens. The General Self-Efficacy Scale (GSES) was used to assess selfefficacy at discharge and at month 1 after discharge. The 
primary endpoint was the occurrence of PICC-associated infection. The secondary endpoints were catheter blockage and catheter displacement.

\section{Statistical analysis}

SPSS v18.0 (Chicago, USA) was used for statistical analysis. Measurement data were expressed as the mean \pm standard deviation $(x \pm s)$ and analyzed with independent sample $t$-tests (intergroup comparisons) or paired $t$-tests (intragroup comparisons). Count data were expressed as a frequency (percent) [n (\%)] and analyzed with the $\chi^{2}$ test. $\mathrm{P}<0.05$ was considered statistically significant.

\section{Results}

A total of 159 cancer patients who received chemotherapy at our hospital between July 2017 and December 2018 and randomly divided the patients to an observation group $(\mathrm{n}=79)$ and a control group $(n=80)$. The basic characters of the two groups were similar and comparable $(\mathrm{P}>0.05)$ (Table 1) (Figure 1).

\section{Infection rate}

Among the 159 patients receiving chemotherapy, 26 (16.35\%) experienced PICC-associated infections.

\section{Pathogens}

Pathogens including gram-positive bacteria $(13,50.00 \%)$, gram-negative bacteria $(8,30.77 \%)$, and fungi $(5,19.23 \%)$ were identified.

\section{Univariate analysis of PICC-associated infections}

Univariate analysis showed that sex, puncture site, and steroid use were unrelated to PICC-associated infections $(\mathrm{P}>0.05)$, whereas PICC indwelling time, WBC counts, a history of diabetes, and immunity were significantly related to PICC-associated infections $(\mathrm{P}<0.05)$ (Table 2).

\section{Self-efficacy scores before and after the intervention}

No significant between-group difference was observed before the intervention $(\mathrm{P}>0.05)$. After the intervention, the self-efficacy score was improved in both groups, especially in the observation group $(\mathrm{P}<0.05$, Table 3).

\section{Complication rate}

Catheter infection, catheter blockage, and catheter displacement occurred in both groups, but the incidence was lower in the observation group $(\mathrm{P}<0.05)$ (Table 4).

\section{Discussion}

For cancer patients, chemotherapy through a PICC effectively reduces discomfort associated with frequent punctures and has been widely used to support longterm application and chemotherapy administration, providing a safe, reliable, and long-term infusion route (10-12). However, PICCs are invasive and have a high risk of infection, which may affect treatment outcomes. A variety of complications after long-term catheterization was observed at the meanwhile, such as such as bleeding at the puncture site, mechanical phlebitis, local infection,

Table 1 Baseline characteristics of patients between two groups

\begin{tabular}{|c|c|c|c|c|}
\hline Factors & Control group $(n=80)$ & Observation group $(n=79)$ & $t / \chi^{2}$ & $P$ \\
\hline \multicolumn{5}{|l|}{ Gender } \\
\hline Male & 21 & 19 & 0.102 & 0.749 \\
\hline Female & 59 & 60 & & \\
\hline$\leq$ Junior high school & 17 & 16 & 0.155 & 0.925 \\
\hline Senior high school-bachelor & 38 & 36 & & \\
\hline$\geq$ Bachelor & 25 & 27 & & \\
\hline
\end{tabular}

Table 1 (continued) 
Table 1 (continued)

\begin{tabular}{|c|c|c|c|c|}
\hline Factors & Control group $(n=80)$ & Observation group $(n=79)$ & $t / \chi^{2}$ & $P$ \\
\hline \multicolumn{5}{|l|}{ Complication } \\
\hline Diabetes & 39 & 37 & 0.290 & 0.591 \\
\hline Hypertension & 28 & 32 & & \\
\hline \multicolumn{5}{|l|}{ Smoke } \\
\hline No & 66 & 63 & & \\
\hline \multicolumn{5}{|l|}{ Cancer type } \\
\hline Nasopharyngeal cancer & 22 & 19 & 0.960 & 0.987 \\
\hline Breast cancer & 18 & 17 & & \\
\hline Esophagus cancer & 7 & 8 & & \\
\hline Colorectal cancer & 7 & 6 & & \\
\hline Other types & 4 & 3 & & \\
\hline \multicolumn{5}{|l|}{ PICC time } \\
\hline Once & 54 & 49 & 0.547 & 0.592 \\
\hline$\geq 2$ times & 26 & 30 & & \\
\hline \multicolumn{5}{|l|}{ Puncture position } \\
\hline Basilic vein & 42 & 37 & 0.340 & 0.672 \\
\hline$>30$ & 54 & 49 & 0.529 & 0.497 \\
\hline$\leq 30$ & 26 & 30 & & \\
\hline \multicolumn{5}{|l|}{ Immunologic function } \\
\hline Normal & 43 & 41 & 0.474 & 0.621 \\
\hline Weak & 37 & 38 & & \\
\hline \multicolumn{5}{|c|}{ White blood cell count $\left(\times 10^{9} / \mathrm{L}\right)$} \\
\hline$\leq 3.0$ & 35 & 31 & 0.541 & 0.769 \\
\hline$>3.0$ & 45 & 49 & & \\
\hline
\end{tabular}




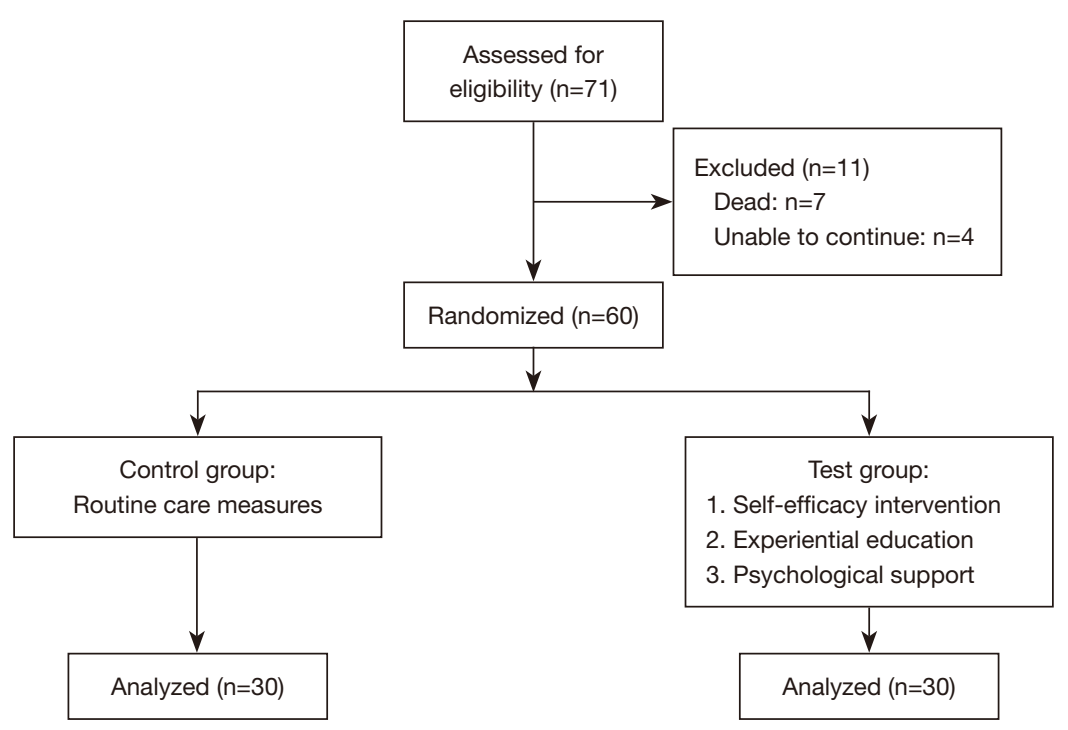

Figure 1 Flow diagram.

Table 2 Univariate analysis of PICC-associated infections

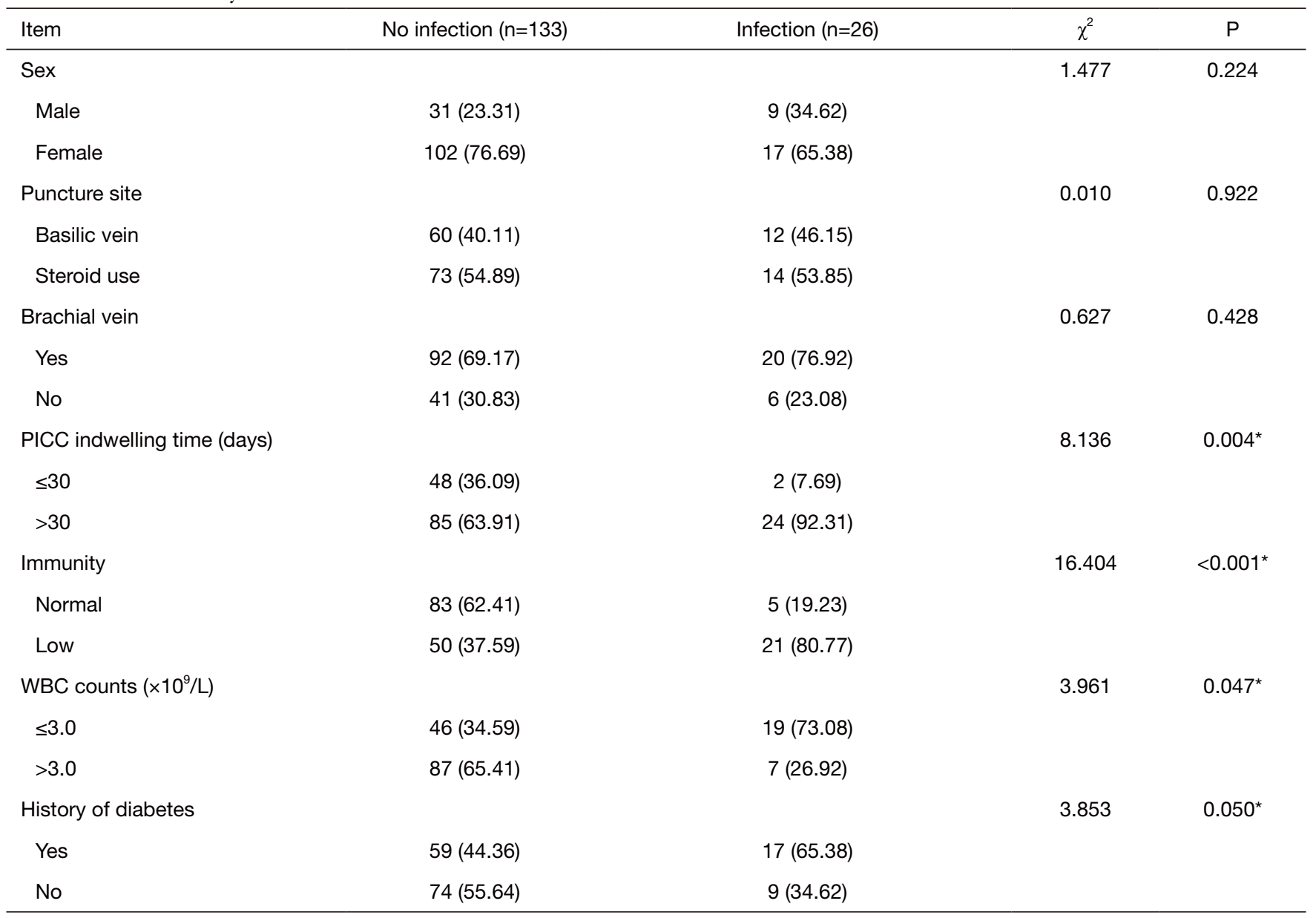

*, P $\leq 0.05$ (statistically significant). PICC, peripherally inserted central catheter. 
Table 3 Self-efficacy score before and after the intervention $(\bar{x} \pm \mathrm{s}$, points)

\begin{tabular}{|c|c|c|c|c|c|}
\hline Group & $\mathrm{n}$ & \multicolumn{2}{|c|}{ Self-efficacy score } & $t$ & $P$ \\
\hline Control group & 59 & $18.56 \pm 3.56$ & $28.45 \pm 5.12$ & 15.226 & $0.000^{\star}$ \\
\hline Observation group & 60 & $18.45 \pm 4.02$ & $24.12 \pm 3.89$ & 9.591 & $0.000^{\star}$ \\
\hline$t$ & & 0.194 & 6.441 & & \\
\hline
\end{tabular}

*, $\mathrm{P} \leq 0.05$ (statistically significant).

Table 4 Complication rate $[\mathrm{n}(\%)]$

\begin{tabular}{|c|c|c|c|c|c|}
\hline Group & $\mathrm{n}$ & Catheter infection & Catheter blockage & Catheter displacement & Total \\
\hline Control group & 60 & 22 (84.62) & 5 (6.09) & $10(83.33)$ & $37(88.10)$ \\
\hline$\chi^{2}$ & & 15.562 & 1.527 & 5.783 & 31.662 \\
\hline$P$ & & $<0.001^{*}$ & 0.217 & $0.016^{\star}$ & $<0.001^{*}$ \\
\hline
\end{tabular}

*, $\mathrm{P} \leq 0.05$ (statistically significant).

catheter blockage, catheter drift or prolapse, catheter rupture or rupture, the most important of which is catheterrelated infection. Catheter related blood stream infections (CRBSI) is an important complication of long-term deep vein catheterization and the most serious complication after PICC puncture (13). Due to tumor patients have poor immunity and long chemotherapy time, PICCassociated infection may make the treatment situation more complicated and severely destroy the patient's quality of life. Therefore, risk factors for PICC-associated infections should be investigated, and targeted intervention measures must be developed to manage and prevent infection $(14,15)$.

This study showed that 26 of 159 PICC patients (16.35\%) experienced PICC-associated infections; the pathogens identified included gram-positive bacteria (13, $50.00 \%)$, gram-negative bacteria $(8,30.77 \%)$, and fungi (5, $19.23 \%$ ), suggesting that nurses should focus on hygiene and sterile techniques during PICC insertion to minimize the likelihood of infection. Univariate analysis showed that PICC indwelling time, steroid use, WBC counts, a history of diabetes, and immunity were risk factors for PICC-associated infections. This finding can be explained by $(16,17)$ cancer patients often having physiological dysfunction and consumption syndrome, as well as chronic diseases such as hypertension and diabetes, resulting in a weakened ability to fight germs and low immunity due to long-term chemotherapy, which increases the risk of bacterial infection. The following interventions are recommended for cancer patients undergoing chemotherapy through a PICC to reduce the risk of infection (18-20): (I) comprehensive evaluation of the patient's physical condition and infection-related factors before PICC insertion; (II) a standardized PICC procedure, regular staff training, and compliance with disinfection and sterile procedures; and (III) standardized PICC maintenance and close monitoring of redness and swelling at the puncture site with a documented maintenance schedule.

Studies $(21,22)$ show that self-efficacy interventions enhance self-efficacy, self-management, patient confidence, and patient-nurse relationships during chemotherapy through a PICC. Moreover, nurses supervise and encourage patients to engage in PICC care via ongoing monitoring, which improves patient confidence and encourages patients to live with their conditions. This study showed that a self-efficacy intervention improved self-efficacy scores, suggesting that self-efficacy interventions improve selfefficacy and self-management of indwelling PICCs. Moreover, self-efficacy interventions significantly reduce the complication rate $(16.67 \%$ vs. $88.10 \%)$, suggesting that selfefficacy interventions reduce the complication rate associated with indwelling PICCs. Taken together, the risk factors for infection in PICC nursing process are mainly related to the 
nursing staff's puncture skills, catheter care level, catheter indwelling time, strict aseptic operation and other factors. It is necessary to improve the nursing work standards and working rules for the above points. Moreover, personnel conduct professional skills training is important to reduce the risk of infection and reduce the suffering of patients.

In summary, for cancer patients undergoing chemotherapy through a PICC, self-efficacy interventions improve self-management and reduce complications. PICC indwelling time, WBC count, a history of diabetes, and immunity are independent risk factors for PICC-associated infections, suggesting that sterile procedures should be followed and PICC maintenance should be standardized to reduce the risk of PICC-associated infections.

\section{Acknowledgments}

Funding: (I) Nantong Science and Technology Bureau Project (JCZ19044); (II) Youth Program of Nantong Municipal Health Commission of Jiangsu Province (QA2019001); (III) General Program of Nantong Municipal Health Commission of Jiangsu Province (MB2019011).

\section{Footnote}

Reporting Checklist: The authors have completed the CONSORT reporting checklist. Available at https://dx.doi. org/10.21037/apm-21-1848

Trial Protocol: Available at https://dx.doi.org/10.21037/apm21-1848

Data Sharing Statement: Available at https://dx.doi. org/10.21037/apm-21-1848

Conflicts of Interest: All authors have completed the ICMJE uniform disclosure form (available at https://dx.doi. org/10.21037/apm-21-1848). The authors have no conflicts of interest to declare.

Ethical Statement: The authors are accountable for all aspects of the work in ensuring that questions related to the accuracy or integrity of any part of the work are appropriately investigated and resolved. The study was conducted in accordance with the Declaration of Helsinki (as revised in 2013). The study was approved by the Ethics Committee of Affiliated Hospital of Nantong University. Written informed consent was obtained from all patients.
Open Access Statement: This is an Open Access article distributed in accordance with the Creative Commons Attribution-NonCommercial-NoDerivs 4.0 International License (CC BY-NC-ND 4.0), which permits the noncommercial replication and distribution of the article with the strict proviso that no changes or edits are made and the original work is properly cited (including links to both the formal publication through the relevant DOI and the license). See: https://creativecommons.org/licenses/by-nc-nd/4.0/.

\section{References}

1. Özer A, Tatar T, Kocak B, et al. Angiosarcoma at femoral artery puncture site; a diagnostic dilemma. Turk Kardiyol Dern Ars 2019;47:698-700.

2. Huang $\mathrm{W}, \mathrm{Xu} \mathrm{J}$. The role of sterile chitosan-based dressing in reducing complications related to a peripherally inserted central catheter in patients with hematological tumors. Ann Palliat Med 2020;9:2037-44.

3. Thomsen T, Aadahl M, Beyer N, et al. The efficacy of motivational counselling and SMS reminders on daily sitting time in patients with rheumatoid arthritis: a randomised controlled trial. Ann Rheum Dis 2017;76:1603-6.

4. Johansson E, Hammarskjöld F, Lundberg D, et al. Advantages and disadvantages of peripherally inserted central venous catheters (PICC) compared to other central venous lines: a systematic review of the literature. Acta Oncol 2013;52:886-92.

5. Fang S, Yang J, Song L, et al. Comparison of three types of central venous catheters in patients with malignant tumor receiving chemotherapy. Patient Prefer Adherence 2017;11:1197-204.

6. Al-Asadi O, Almusarhed M, Eldeeb H. Predictive risk factors of venous thromboembolism (VTE) associated with peripherally inserted central catheters (PICC) in ambulant solid cancer patients: retrospective single Centre cohort study. Thromb J 2019;17:2.

7. Inoue S, Yoshida T, Nishino T, et al. Safe central venous catheters for esophageal cancer treatment. J Med Invest 2020;67:298-303.

8. Giustino G, Mehran R, Bansilal S, et al. Safety and Efficacy of Bivalirudin in Patients With Diabetes Mellitus Undergoing Percutaneous Coronary Intervention: From the REPLACE-2, ACUITY and HORIZONS-AMI Trials. Am J Cardiol 2016;118:6-16.

9. Liu W, Wang QP, Guo J. Prognostic significance of long non-coding RNA DANCR expression in human cancers: 
A systematic review and meta-analysis. Biosci Rep 2019.

10. Campagna S, Gonella S, Berchialla P, et al. Can Peripherally Inserted Central Catheters Be Safely Placed in Patients with Cancer Receiving Chemotherapy? A Retrospective Study of Almost 400,000 Catheter-Days. Oncologist 2019;24:e953-9.

11. Feldstain A, Lebel S, Chasen MR. An interdisciplinary palliative rehabilitation intervention bolstering general self-efficacy to attenuate symptoms of depression in patients living with advanced cancer. Support Care Cancer 2016;24:109-17.

12. Hu L, Tao H, Xu X, et al. Factors for peripherally inserted central catheters care delay in cancer patients during the COVID-19 pandemic. Ann Palliat Med 2020;9:3818-29.

13. Garcia X, Pye S, Tang X, et al. Catheter-Associated Blood Stream Infections in Intracardiac Lines. J Pediatr Intensive Care 2017;6:159-64.

14. Qi F, Cheng H, Yuan X, et al. Comparison of PICC and TIVAP in chemotherapy for patients with thyroid cancer. Oncol Lett 2020;20:1657-62.

15. Lee SY, Shin DH, Kim JS, et al. The Effect of Sex and Anthropometry on Clinical Outcomes in Patients Undergoing Percutaneous Coronary Intervention for Complex Coronary Lesions. Yonsei Med J 2017;58:296-304.

16. Mielke D, Wittig A, Teichgräber U. Peripherally inserted central venous catheter (PICC) in outpatient and

Cite this article as: Liu X, Tao S, Ji H, Chen S, Gu Y, Jin X. Risk factors for peripherally inserted central catheter (PICC)associated infections in patients receiving chemotherapy and the preventive effect of a self-efficacy intervention program: a randomized controlled trial. Ann Palliat Med 2021;10(9):93989405. doi: 10.21037/apm-21-1848 inpatient oncological treatment. Support Care Cancer 2020;28:4753-60.

17. Suzuki J, Sasahara T, Toshima M, et al. Peripherally inserted central catheter-related bloodstream infection due to Tsukamurella pulmonis: a case report and literature review. BMC Infect Dis 2017;17:677.

18. Dencker D, Taudorf $M$, Luk NH, et al. Frequency and Effect of Access-Related Vascular Injury and Subsequent Vascular Intervention After Transcatheter Aortic Valve Replacement. Am J Cardiol 2016;118:1244-50.

19. Cotogni P, Pittiruti M. Focus on peripherally inserted central catheters in critically ill patients. World J Crit Care Med 2014;3:80-94.

20. Kwon S, Son SM, Lee SH, et al. Outcomes of bedside peripherally inserted central catheter placement: a retrospective study at a single institution. Acute Crit Care 2020;35:31-7.

21. Guo J, Chen W, Wang G, et al. Safety and Efficacy of Using a Single Transradial MAC Guiding Catheter for Coronary Angiography and Intervention in Patients with ST Elevation Myocardial Infarction. J Interv Cardiol 2017;30:33-42.

22. Yuan Y, Qiu H, Hu XY, et al. Risk Factors of Contrastinduced Acute Kidney Injury in Patients Undergoing Emergency Percutaneous Coronary Intervention. Chin Med J (Engl) 2017;130:45-50. 